Research review paper

\title{
Multiscale heterogeneity in filamentous microbes
}

\author{
Boris Zacchetti ${ }^{\mathrm{a}}$, Han A.B. Wösten ${ }^{\mathrm{b}}$, Dennis Claessen ${ }^{\mathrm{a}, *}$ \\ a Microbial Biotechnology, Institute of Biology, Leiden University, Sylviusweg 72, 2333, BE, Leiden, The Netherlands. \\ ${ }^{\mathrm{b}}$ Microbiology, Department of Biology, Utrecht University, Padualaan 8, 3584, CH, Utrecht, The Netherlands.
}

A R T I C L E I N F O

\section{Keywords:}

Heterogeneity

Fungi

Actinomycetes

Biotechnology

Multicellularity

\begin{abstract}
A B S T R A C T
Microbial cells within clonal populations can display different morphologies or carry out different tasks. This heterogeneity is beneficial at the population level and allows microbes to spread risk or separate incompatible activities. Heterogeneity is also evident in filamentous bacteria and fungi, which form mycelial networks consisting of interconnected hyphae. Here, heterogeneity is observed between clonal mycelial particles, between different zones of colonies, between adjacent hyphae and even between adjacent compartments of individual hyphae. In this review, we compare this multiscale heterogeneity in filamentous bacteria and fungi and discuss the underlying mechanisms. These mechanisms might provide targets to improve the exploitability of these organisms as cell factories in the biotech sector.
\end{abstract}

\section{Introduction}

One of the assumptions in microbiology was that cells in a monoclonal microbial population would be phenotypically indistinguishable when provided with a constant environment. Over the last two decades, however, the development of high-throughput analytical techniques has enabled microbiologists to study large numbers of cells at the individual level (Binder et al., 2017; Brehm-Stecher and Johnson, 2004; Davis and Isberg, 2016) and to unambiguously demonstrate that processes such as metabolism, transcription, translation and protein secretion are heterogeneous in space and time across cells (Ackermann, 2015; Avery, 2006; Smits et al., 2006; van Boxtel et al., 2017; Veening et al., 2008b; Wösten et al., 2013). Examples of these heterogeneities have been documented in a wide range of microorganisms, including some of the best-characterized prokaryotic and eukaryotic model organisms (e.g. Escherichia coli, Bacillus subtilis and Saccharomyces cerevisiae, among others) (Chastanet et al., 2010; Elowitz et al., 2002; Levy et al., 2012; Maamar et al., 2007). While heterogeneity has been mostly addressed in unicellular microbes, it is also evident in multicellular species. In this review, we will focus on heterogeneities in filamentous microorganisms that are employed as cell factories in the industrial sector. We will discuss the consequences (disadvantages and benefits) of these heterogeneities and the mechanisms through which these are established.

\section{The consequences of phenotypic heterogeneity}

Phenotypic heterogeneity allows microbes to withstand environmental fluctuations and carry out specialized functions at the level of single cells. In their natural habitats, microbes are confronted with rapidly changing environmental conditions. The best-known mechanism to withstand such changes is to modulate gene expression (Jacob and Monod, 1961). Changes in gene expression can lead to profound phenotypic changes, including cellular differentiation. Many microbes, however, ensure that a number of cells within a clonal population already possess certain defensive traits, even when the corresponding environmental stimulus is not present (Philippi and Seger, 1989). As a consequence of this strategy, commonly referred to as bethedging, only a fraction of the cells will pay the cost (e.g. reduced metabolic proficiency) associated with the expression of those genes conferring potentially useful features. Should the environmental conditions become adverse and change in their favor, these cells would already be equipped to withstand the altered conditions and are therefore more likely to survive. This behavior is beneficial to the entire population (Grimbergen et al., 2015).

Bet-hedging and phenotypic heterogeneity have been extensively studied in Bacillus subtilis. This Gram-positive bacterium forms endospores when exposed to stress conditions (e.g. starvation or the presence of toxins) (Errington, 2003; Higgins and Dworkin, 2012). These spores are metabolically dormant and highly resistant to extreme temperatures, desiccation and ionizing radiation. When environmental conditions suitable for growth are restored, spores germinate to

\footnotetext{
* Corresponding author.

E-mail address: D.Claessen@biology.leidenuniv.nl (D. Claessen).
} 


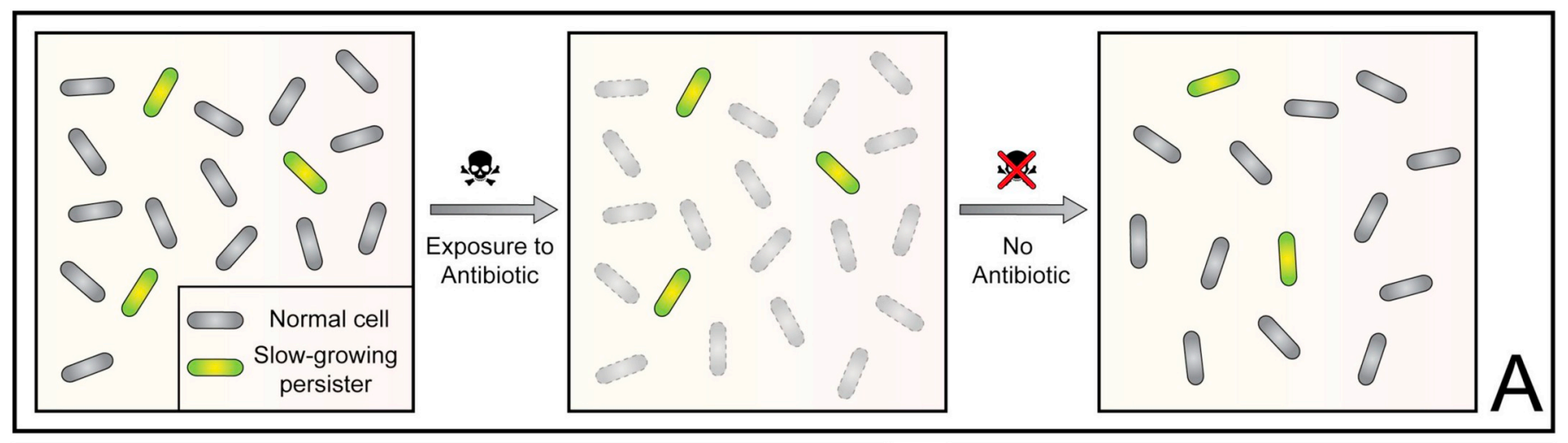

Cyanobacteria
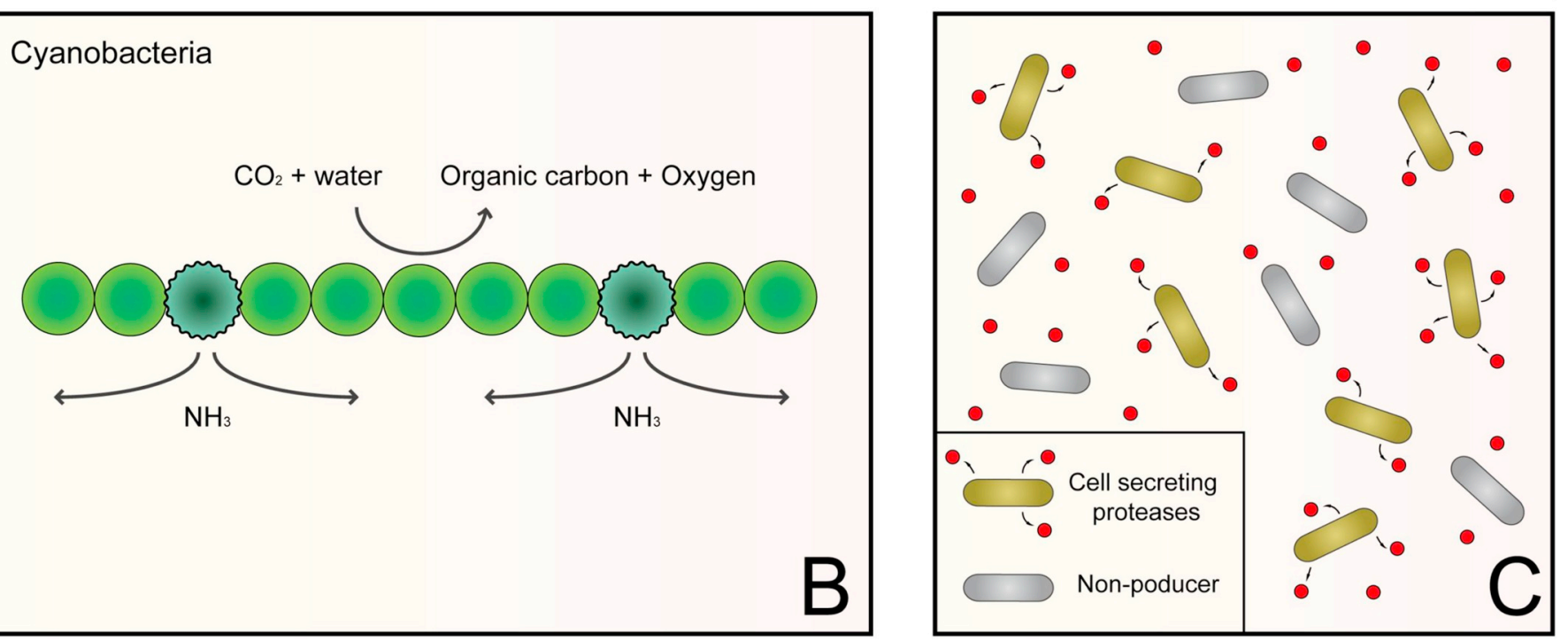

Fig. 1. Examples and benefits of microbial heterogeneity. (A) Bet-hedging. Microbial clonal populations often contain persisters. Such dormant cells are beneficial in conditions counter-selecting growing cells, for instance due to the presence of an antibiotic. When the normal conditions return, these persisters initiate growth, thereby restoring the population. (B) Division of labor in cyanobacteria. Oxygenic photosynthesis and nitrogen fixation are chemically incompatible processes, since the oxygen produced through photosynthesis inactivates the nitrogenase enzyme required for nitrogen fixation. Cyanobacteria physically separate these processes by forming specialized nitrogen-fixing cells called heterocysts. The fixed nitrogen will diffuse to the neighboring cells, while heterocysts benefit from the organic carbon produced by cells engaging in photosynthesis. (C) Production of secreted molecules. The production and secretion of molecules that benefit the entire population is often carried out by only a subset of cells. In this example, some Bacillus subtilis cells secrete proteases that provide hydrolyzed nutrients to the whole population under nutrient-limiting conditions. It is not clear whether the non-secreting cells participate in other ways to the overall survival of the population.

establish colonies of vegetative cells. A bet-hedging control of sporulation has two main advantages. On the one hand, it assures that not all cells commit themselves to sporulation, which is notoriously a lengthy and irreversible process (Chastanet et al., 2010; Russell et al., 2017). In this way, when only a fraction of the cells sporulates, the nonsporulating ones can quickly reinitiate growth in case the stress condition turns out to be transient, hence preventing the population from becoming outnumbered by competitors. On the other hand, since environmental changes are sometimes too harmful for the sporulation process to complete, the stochastic initiation of sporulation ensures that some cells undergo sporulation even in the absence of adverse conditions (Siebring et al., 2014; Veening et al., 2008c).

Another canonical example of the benefits of microbial individuality is that of bacterial persistence. A fraction of Escherichia coli cells forms metabolically dormant persister cells that are able to withstand various environmental insults, such as the prolonged exposure to antibiotics (Balaban et al., 2004), and to resume growth when the original conditions are restored (Fig. 1). Sub-populations of non-growing persisters that survive exposure to antibiotics have also been reported in Salmonella (Claudi et al., 2014; Helaine et al., 2014) and Mycobacterium (Manina et al., 2015). The appearance of persisters can also occur when cells are not challenged by antimicrobials (Balaban et al., 2004), although stressful conditions can enhance their abundance within a population (Dörr et al., 2010; Johnson and Levin, 2013; Mulcahy et al., 2010). A similar strategy has been reported in Saccharomyces cerevisiae. Within clonal populations of this yeast, certain individuals are characterized by lower growth rates and concomitantly possess higher resistance to heat shock due to the accumulation of the protecting disaccharide trehalose (Levy et al., 2012). Notably, experimentally tuning growth rates of $S$. cerevisiae using chemostat cultures has highlighted that many of the genes activated upon heat stress are also active under conditions of slow growth, which is again substantiated by the observation that cells that grow slowly are more resistant to heat stress (Lu et al., 2009).

Recent studies have shown that bet-hedging strategies culminating in phenotypic heterogeneity also become evident when microbial cells are exposed to fluctuating nutritional regimes (Kotte et al., 2014; Solopova et al., 2014; van Heerden et al., 2014). This is no surprise when considering the rapidly changing nutritional conditions that microbial cells endure in their natural environments. When exposed to mixtures of carbon source, microbes typically consume them in a sequential manner. As a consequence, distinct growth phases are observed that are separated by a lag phase. During this phase, cells are believed to undergo the physiological adaptations needed for the uptake and consumption of the second carbon source. This behavior is known as diauxie (Monod, 1949). The diauxic shift in Lactococcus lactis 
is explained by the fact that only a limited number of cells is able to metabolize the second carbon source. Interestingly, these cells emerge when the preferred carbon source is still present (Solopova et al., 2014). The decision to commit to the metabolism of the less preferred source depends on the metabolic state of the cell prior to the depletion of the preferred carbon source, while the number of cells enacting the shift is inversely proportional to the abundance of the first carbon source. This mechanism provides an alternative explanation for the decades-old concept of metabolic adaptation during diauxic shifts, which may also be relevant for other lag phases observed in microbiology.

While bet-hedging is beneficial in unpredictable and fluctuating environments, phenotypical heterogeneity can also be advantageous in non-fluctuating conditions, for instance when different processes have to be carried out simultaneously within a clonal population. This socalled division of labor is characterized by the coexistence of subpopulations of cells specialized in performing complementary tasks (van Gestel et al., 2015a, 2015b; Zhang et al., 2016). Under nutrientlimiting conditions, B. subtilis secretes subtilisin E, which degrades proteins into small peptides that are accessible to all community members (Veening et al., 2008a). Single-cell measurements have revealed that only a minority of cells produce and secrete this protease, indicating that only a few members of the clonal population pay the cost associated with its production. It is not yet clear whether this strategy represents a form of pure altruism whereby the producing cells pay the production-associated costs for the benefit of the entire population, or whether it represents a cooperative behavior in that both the producer and the recipient cells mutually benefit from each other. Numerous are the other reported examples where some cells pay the cost for the benefit of the entire population; these include Salmonella enterica (Arnoldini et al., 2014; Diard et al., 2013), Myxococcus xanthus (Velicer et al., 2000), and certain protozoans (Strassmann et al., 2000). M. xanthus represents perhaps the most spectacular example of the commitment of subsets of cells within a given population to a specific function. In the presence of excess nutrients, $M$. xanthus establishes a motile group of cells called a swarm. The swarm explores the environment to forage for nutrients or predate on other bacteria (Reichenbach, 1999). Upon starvation, growth is arrested, and a developmental program is initiated that culminates in the formation of spore-bearing fruiting bodies. Three distinct subpopulations of cells contribute to the formation of fruiting bodies. While only $10 \%$ of cells differentiate into spores, roughly $30 \%$ form peripheral rods on the outer surface of the fruiting body, while the remaining fraction undergoes programmed cell lysis (Nariya and Inouye, 2008; O'Connor and Zusman, 1991; Wireman and Dworkin, 1977). The fact that such a major fraction of the population undergoes PCD is a remarkable example of social behavior, with the lysing cells providing nutrients and energy for sporulation to complete and in turn ensure the propagation of their genome (Berleman et al., 2006; Wireman and Dworkin, 1977).

In some microorganisms, division of labor is employed as a strategy to perform incompatible metabolic processes (de Lorenzo et al., 2015; Johnson et al., 2012; Levine et al., 2013). The best-known example of this strategy is the spatial segregation of nitrogen fixation and photosynthesis in cyanobacteria (Mitsui et al., 1986) (Fig. 1). The nitrogenase enzyme required for nitrogen fixation is sensitive to oxygen, the product of photosynthesis. For this reason, some cyanobacteria generate specialized cells called heterocysts, which are specialized in nitrogen fixation while lacking the oxygenic photosystem (Adams, 2000). Heterocysts also have a different cell wall composition that contributes to the exclusion of oxygen to protect the nitrogenase enzyme (Kumar et al., 2010). On the other hand, non-heterocystous cyanobacteria separate photosynthesis and nitrogen fixation by temporally segregating the two incompatible processes (Berman-Frank et al., 2001).

\section{Mechanisms underlying individuality in unicellular microbes}

When compared to higher multicellular eukaryotes, the regulation of gene expression in microorganisms (especially in prokaryotes) appears to be controlled by only a handful of mechanisms. As a consequence, one would expect any given gene to be expressed at a similar level in isogenic microbial cells exposed to the same environmental conditions. However, it is well accepted that bacterial gene expression is subject to intrinsic noise. In a pioneering study that paved the road for the nascent field of microbial heterogeneity, cells of $E$. coli were engineered to express two distinguishable fluorescent proteins under control of the same promoter. Major differences in the expression of these reporters were detected both within and between cells, indicating that gene expression is subject to intrinsic fluctuations (Elowitz et al., 2002). It is interesting to note that the level of transcription negatively correlates with the heterogeneity in fluorescence emission, indicating that intrinsic noise is more pronounced at low transcriptional levels. Extensive work has shown that a considerable degree of heterogeneity between microbial cells originates from the fact that transcription and translation occur in so called pulses or "bursts" (Blake et al., 2003; Cai et al., 2006; Golding et al., 2005; Ozbudak et al., 2002). Since these stochastic pulses are asynchronous between cells, distinct subpopulations can evolve and coexist. A number of studies on B. subtilis have shown how pulsating genetic circuits control processes such as the development of competence, the onset of sporulation, and the response to environmental stresses (Levine et al., 2012; Locke et al., 2011; Süel et al., 2007; Young et al., 2013). Notably, single cell measurements in both prokaryotic and eukaryotic microbes have revealed disparities in the degree of transcriptional noise between different genes within a single cell. These disparities are seemingly not arbitrary, as the transcription of housekeeping genes is generally less noisy than that of genes associated with stress or dispensable metabolic functions (Newman et al., 2006; Silander et al., 2012; Taniguchi et al., 2010).

Phenotypic heterogeneity between cells can also originate from transcriptional differences caused by cellular processes. Several studies have shown that physiological factors such as growth rate and cell cycle stage can substantially influence gene expression (Berthoumieux et al., 2013; Slavov and Botstein, 2013). Single-cell studies have recently shed light on the importance of the feedback of growth in causing heterogeneity. For example, fluctuations in the expression of metabolic genes can lead to fluctuations in the growth rate of individual cells, which in turn not only perturb the expression of other metabolic genes, but also of unrelated gene networks (Kiviet et al., 2014; Klumpp and Hwa, 2014; Tan et al., 2009). Deterministic choices can also be a source of cell-tocell heterogeneity. For example, metal ion scarcity leads to a growth arrest in newborn daughter cells of $S$. cerevisiae (i.e. cells which have not budded yet). As a consequence, two populations of cells emerge: older dividing cells and younger non-dividing cells (Avraham et al., 2013). This is explained by the fact that the vacuole, which is the reservoir for metals, is not propagated to daughter cells, while it is maintained in the mother cells which keep dividing. This strategy results in higher fitness under zinc-limiting conditions than in a mutant strain where vacuole segregation occurs homogeneously. In the latter case, zinc is diluted in fact to an extent that eventually impedes cellular division.

The generation of phenotypic heterogeneity and multi-stability have also been the subject for numerous mathematical models. Such models are important for better understanding the principles behind bet-hedging and provide predictive value that can be tested experimentally. Recent models include the stochastic nature of cellular processes and provide a powerful framework for understanding phenotypic switching between different cellular states. We here wish to refer to some excellent papers for readers interested to learn more about this aspect (see e.g. Henson, 2003; Jia et al., 2014; Meister et al., 2014; Wilkinson, 2009, and references therein).

\section{Heterogeneity in filamentous organisms}

The features of phenotypic heterogeneity discussed in the previous 
sections relate to unicellular microorganisms, the cells of which are, at least under most conditions, spatially separated from one-another. In contrast, many multicellular microbes such as filamentous actinomycetes and fungi grow by means of interconnected filaments that only physically separate into unicellular propagules during the reproductive phase (Claessen et al., 2014). From a morphological perspective, the mode of growth of filamentous actinomycetes is similar to that of filamentous fungi. This is the reason why, despite bearing the structural features of bacteria, actinomycetes were originally believed to be fungi (Goodfellow et al., 1983). In contrast to most unicellular organisms, filamentous fungi and actinomycetes possess a complex life cycle characterized by distinct developmental stages and the co-existence of different specialized cells. Both kinds of microorganisms propagate via spores, dormant cells equipped to withstand harsh environmental conditions (Barka et al., 2016; Walker and White, 2005). Spores germinate under favorable conditions, leading to germ tubes that elongate to form thread-like cells called hyphae. Hyphae of filamentous fungi and actinomycetes have a diameter of about $2-10 \mu \mathrm{m}$ and $0.5-2 \mu \mathrm{m}$, respectively. They elongate at their tip (or apex), while new hyphae emerge subapically by branching (Flärdh, 2010; Riquelme, 2013). The combination of apical growth and branching yields an interwoven cellular network called a mycelium. The growing vegetative mycelium (also called substrate mycelium) colonizes the environment by radiating leading hyphae from peripheral regions of the colony. The encountered polymeric substrates are degraded by means of secreted hydrolytic enzymes and the degradation products are internalized by the cells to serve as nutrients (Barka et al., 2016). When nutrients become scarce, colonies of filamentous microbes develop into complex multicellular consortia of different cell types (Chater, 1998; Krijgsheld et al., 2013a; Kues and Liu, 2000). For instance, while the peripheral regions of Streptomyces colonies proceed with vegetative growth, more central and non-growing parts of the colony undergo an ordered process of chemical and morphological differentiation (Borkovich and Ebbole, 2010; Manteca et al., 2005a). Such chemical differentiation is responsible for the production of various secondary metabolites, many of which are exploited for commercial use (Barka et al., 2016; Bérdy, 2005; Hopwood, 2007) (see below). Coinciding with this chemical differentiation, specialized aerial hyphae emerge on the colony surface. The aerial hyphae of actinomycetes differentiate into chains of unigenomic spores, while those of fungi form more elaborate asexual (e.g. condidiophores) or sexual reproductive structures (e.g. mushrooms).

When grown in close proximity to certain yeasts (e.g S. cerevisiae) or when faced with conditions of nutrient scarcity, some streptomycetes (i.e. the best-studied and industrially the most relevant representatives of the actinomycetes) form so-called "exploring" cells. These cells can travel over nutrient-void abiotic surfaces and promote the spreading of colonies over large surfaces (Jones et al., 2017). Despite being morphologically similar to aerial hyphae in that they do not branch, exploratory hyphae miss the hydrophobic coating which is distinctive of aerial structures, and hence represent a new cellular type with features of both vegetative and aerial hyphae. This functional differentiation is reminiscent of a bet-hedging strategy, with explorer cells allowing dispersal in those cases in which sporulation might be too costly or take too long to complete (Jones and Elliot, 2017).

Although the distinction in structure and function between vegetative and reproductive hyphae has been known for many decades (Chater, 1998), we are now beginning to understand that heterogeneity is also evident in mycelial aggregates growing in liquid environments, between zones of mycelia, between adjacent hyphae within a colony zone and even between compartments of a single hypha. In the following sections we will first describe methodologies used to study heterogeneity in filamentous microbial populations before discussing intra- and inter-hyphal heterogeneity in the vegetative mycelium of streptomycetes and filamentous fungi on solid substrates. We will then discuss heterogeneity in liquid-grown mycelia and its effect on production performances of commercially valuable products.

\subsection{Techniques for studying phenotypic heterogeneity in filamentous} microbes

The analysis of heterogeneity relies on techniques that enable the qualitative and quantitative assessment of physiological traits at the single cell level. Microfluidics and flow-cytometry approaches have contributed strongly to the study of phenotypic heterogeneity in unicellular microbes (Ackermann, 2015; Avery, 2006; Davis and Isberg, 2016). Microfluidics systems use miniaturized growth chambers that allow growth of various cell types in a finely controlled microenvironment (Delvigne et al., 2017). Because of this feature, differences observed between cells can exclusively be attributed to intrinsic cellular heterogeneity and not to varying environmental conditions. Most microfluidics devices can easily be accommodated in various type of microscopes which, in turn, allows to finely track growth of single cells, but also to use fluorescent reporters (i.e. fluorescent proteins and dyes). Different concepts have been developed in recent years, encompassing a large range of sizes and designs (Grunberger et al., 2014; Hol and Dekker, 2014; Reece et al., 2016; Wu and Dekker, 2016). The use of microfluidics for studying filamentous organisms is limited (Grünberger et al., 2013), which relates to the fact that mycelia typically form large multicellular structures formed by hyphae growing and branching in three dimensions. As a result, the mycelium easily grows out of the crafted chambers. Microfluidic approaches would be feasible only by confining growth to two dimensions, which could however dramatically affect the physiology of the mycelium.

While microfluidic approaches are valuable for studying the behaviour of individual cells, flow cytometry allows for the rapid analysis of large numbers of cells. Multiple parameters are analysed, including cell size, granularity, and fluorescence. As in the case of microfluidics, suspended cells or cell aggregates (mainly encountered in filamentous microbes) sense a constant environment in well-mixed submerged cultures, which allows to directly designate the observed heterogeneity as an intrinsic property of the system under analysis. Notably, conventional flow cytometers are not suitable for the analysis of mycelial particles, due to the large size of these structures. However, a number of cytometric apparatuses are nowadays available that were specifically developed for large objects and have been successfully used to study differences between mycelial particles within populations of filamentous microbes (de Bekker et al., 2011b; Petrus et al., 2014; van Veluw et al., 2012). These approaches are however limited to the discrimination of heterogeneity between distinct particles and lack the resolution to study heterogeneity within individual particles. To study heterogeneities at a lower scale (e.g. between distinct filaments in individual particles), fluorescence microscopy-based approaches are most commonly used. Alternatively, laser capture microdissection (LCM) can be used to collect individual mycelial sections or even individual filaments, which can be subsequently analysed in a comprehensive manner using -omics or next generation sequencing techniques (de Bekker et al., 2011a, 2011b).

One other technique to study heterogeneity in filamentous microbes is nanoscale secondary ion mass spectrometry (nanoSIMS). nanoSIMS provides information on the molecular and isotopic compositions of various types of biological samples with a high spatial resolution ( $\mathrm{He}$ et al., 2017; Nunez et al., 2017). This technique has recently been used to detect differences in carbon assimilation between adjacent cells of the non-branching actinomycete Microthrix parvicella (Sheik et al., 2016). NanoSIMS can thus be used to characterize metabolic differences between cellular compartments along hyphae.

\subsection{Heterogeneity in the vegetative mycelium of filamentous organisms on solid substrates}

The vegetative mycelium of fungi and streptomycetes simultaneously performs a large number of different tasks. Besides producing and secreting enzymes for nutrient assimilation, mycelia transport 
nutrients and chemically differentiate to produce a plethora of secondary metabolites (Barka et al., 2016; Borkovich and Ebbole, 2010; Hopwood, 2007). Given that many of these metabolites are of great value to industry, much attention has traditionally been focused on the optimization of production performances in filamentous microbes. However, research in this direction has often been performed using "blind" screening procedures rather than strain optimization strategies based on a deep knowledge of the producing organism (Papagianni, 2004). What has for instance been largely ignored so far is where the production of all these compounds occurs within the mycelium, and how approaches to increase productivity correlate with changes in the localization of production.

The vegetative mycelium of several Streptomyces species is heterogeneous with respect to cellular morphology and physiology. More specifically, the vegetative growth of streptomycetes has been found to encompass two phases during which different cell types are formed (Manteca et al., 2005a, 2005b). The young mycelium that is established after spore germination is highly compartmentalized. The approximately $1-\mu \mathrm{m}$-wide compartments are thought to be separated by membrane structures and/or thin peptidoglycan-containing septa (Yagüe et al., 2013; Yagüe et al., 2016). This first compartmentalized mycelium, called MI mycelium, undergoes an ordered process of dismantling, which is followed by a second growth phase during which a multinucleated mycelium is established (MII). The cellular compartments in this mycelium are significantly larger than those formed in the MI mycelium (Manteca et al., 2005b). Following growth, the MII mycelium undergoes a new round of dismantling, while the remaining viable hyphae form reproductive aerial hyphae that grow into the air (Manteca et al., 2007; Manteca et al., 2005a). Both death rounds are the effect of a regulated cell suicide process, which bears close analogies to that of apoptosis in eukaryotic cells. This resemblance is illustrated by indicators such as the disruption of the cell wall and the cell membrane, the degradation of DNA and the release of the cytoplasmic content into the extracellular medium (Manteca et al., 2006). A proteomic characterization of the first apoptotic process in $S$. coelicolor has highlighted that the majority of the $S$. coelicolor proteins involved in the first apoptotic process localize at the cell wall, which thus seems to represent the first target to be dismantled during the PCD process (Manteca et al., 2010). Other proteins participating in cell dismantling are enzymes involved in the metabolism of fatty acids, various hydrolases, catabolic enzymes, and proteases. The activity of these enzymes is accompanied by an increase in membrane permeability and the subsequent leakage of cytosolic components into the extracellular medium. While the process of cellular dismantling has been observed and described in several streptomycetes, virtually nothing is known about its regulation and how it spatially and temporarily correlates with other processes, such as antibiotic production.

Heterogeneity in the vegetative mycelium of filamentous fungi grown on solid substrates occurs between zones of a colony, between neighboring hyphae within a zone and between compartments of a single hypha (Fig. 2). The first reports on inter-zonal heterogeneity focused on protein secretion within the vegetative mycelium of Aspergillus niger and Phanerochaete chrysosporium. Secretion of the starchdegrading enzyme glucoamylase was found to be spatially confined to the peripheral zone of $A$. niger (Wösten et al., 1991), while lignin peroxidases were found to be released within the central zone of colonies of $P$. chrysosporium (Moukha et al., 1993a; Moukha et al., 1993b). Later studies revealed that each zone of an $A$. niger colony has its own secretome composition (Krijgsheld et al., 2012). For instance, 6 and 10 proteins are at least 4-fold more and less abundant, respectively, in the outer zone when compared to an intermediate zone. Interestingly, zonal differences in expression in $A$. niger colonies can be explained by both medium-dependent and medium-independent mechanisms (Levin et al., 2007). The concentration and nature of the carbon source determines about half of the variation in gene expression, whereas the other half is attributed to differentiation processes in the vegetative mycelium
(Levin et al., 2007). The nature of these differentiation processes is not yet known.

Growth at the outer zone of a fungal colony is supported by nutrients in the substrate while the carbon source is exhausted in the central parts of the colony (clearly, the same holds for the mycelia of bacterial species). Here, the hyphae switch from growth on exogenous to endogenous carbon (Pollack et al., 2008). This is accompanied by vacuolization, reduced growth rate, and a decrease of the hyphal diameter. Vacuolar degradation produces sufficient endogenous carbon to support the formation of so-called secondary hyphae. In contrast to streptomycetes, the endogenous carbon source is not released extracellularly and then internalized by other hyphae, but it is transported to the tips of the newly formed filaments. This mechanism secures the nutrients for the fungus rather than enabling competing microbes to absorb them from the environment. Yet, the autolysis of hyphae with the release of nutrients in the medium may also take place in starving zones of colonies (Perez-Leblic et al., 1982). Future studies are needed to reveal which strategy of nutrient recycling is the most dominant in the fungal mycelium.

Enzyme secretion was initially believed to only occur in growing fungal hyphae (Wessels, 1993), whereas it is nowadays clear that it can also occur in non-growing zones of a colony (Krijgsheld et al., 2013b; Levin et al., 2007). How proteins are released into the culture medium by non-growing hyphae is not yet understood knowing that pores in the hyphal cell walls are too small to enable proteins to freely diffuse (Wessels, 1988, 1993). In the case of growing hyphae, such pores are not needed since proteins to be released in the culture medium can $c o$ migrate with the newly synthesized cell wall polysaccharides that are extruded at the tips of growing hyphae and pushed from the inner to the outer part of the cell wall by the turgor pressure and the addition of new cell wall material. Notably, although both growing and non-growing colony zones can secrete proteins in the culture medium, not every zone does so. The sub-peripheral zone of $A$. niger colonies is able to sporulate when environmental conditions are favorable to enable this differentiation process. This zone does not secrete proteins even when sporulation does not take place (Krijgsheld et al., 2013b). A strain of $A$. niger in which the sporulation gene $f b A$ is deleted is no longer able to asexually reproduce and secretes proteins throughout the whole mycelium (Krijgsheld et al., 2013b). The flbA deletion strain also shows a more complex secretome consisting of a number of proteins that are not secreted by the wild-type strain. Together, these observations indicate that sporulation inhibits protein secretion in fungal colonies. From a functional perspective, this appears as coherent behavior. Once hyphae engage in sporulation, it would be inefficient to invest energy in the secretion of enzymes involved in vegetative growth. To further study the phenomenon of sporulation inhibited protein secretion, the impact of deletion of fluG in A. niger was studied (Wang et al., 2015). This gene is at the start of the sporulation program in Aspergillus nidulans. Yet, the flu $G$ mutant strain of $A$. niger was shown not to be affected in sporulation. However, in contrast to wild-type $A$. niger, the deletion strain shows breakdown of starch under the whole colony. From these and other data it was concluded that FluG is a repressor of secretion in the sporulation zone.

Immuno-localization showed that not every hypha within the outer zone of the A. niger colony secretes glucoamylase (Wösten et al., 1991). Indeed, two types of hyphae were shown to exist in this zone; hyphae that highly and hyphae that lowly express the glucoamylase gene (Vinck et al., 2005). This heterogeneity in expression was also observed for other genes encoding hydrolytic enzymes (Vinck et al., 2011). In fact, those hyphae that highly express one of the hydrolase genes were also found to highly express the other hydrolase-encoding genes. In addition, they possess a higher transcriptional and translational activity when compared to hyphae that show lower expression. Nevertheless, both types of hyphae show a similar growth speed, indicating that for secretion to take place a higher transcriptional and translational activity is needed. Our recent findings show that the hyphae showing 

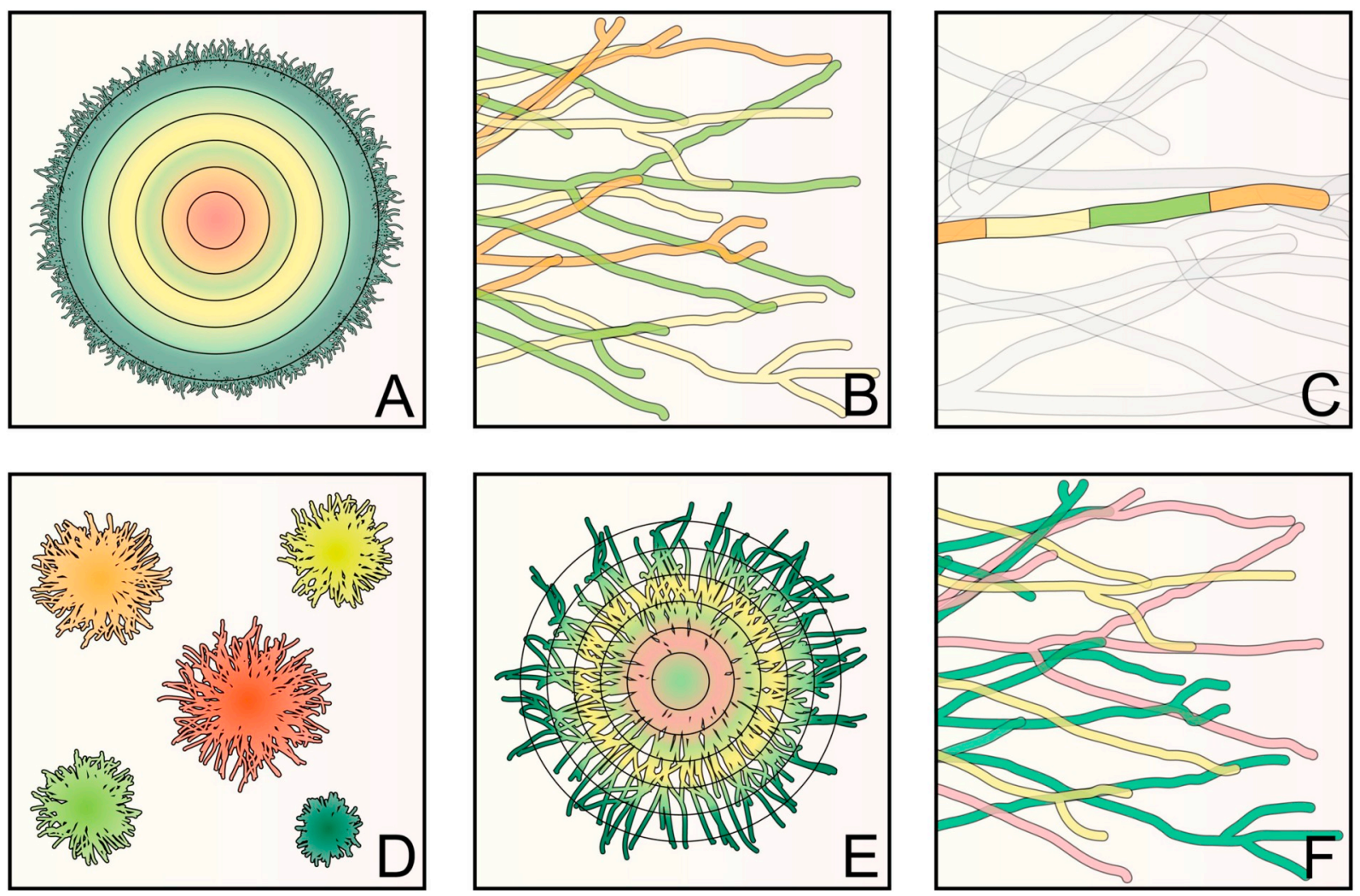

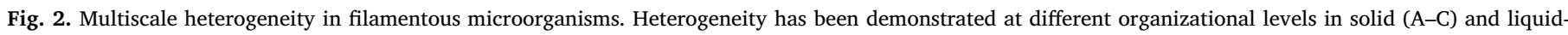

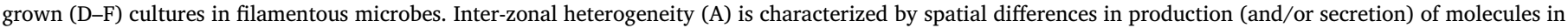

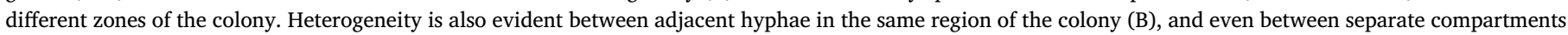

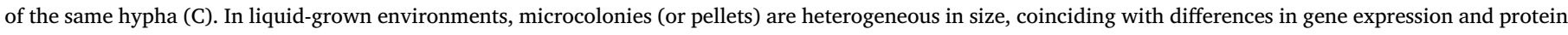

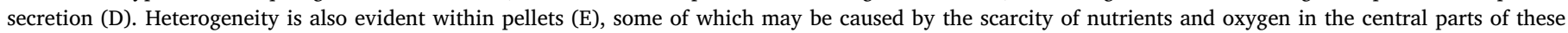
structures. Like in solid-grown cultures, intercompartmental heterogeneity is observed within hyphae in liquid-grown cultures (F).

lower transcriptional and translational activity are also more resistant to heat stress (M Tegelaar, R Bleichrodt and HAB Wösten, unpublished data). Thus, hyphae seem to show a division of labor strategy at the periphery of Aspergillus colonies.

Division of labor is also evident between hyphal compartments of $A$. niger (Tegelaar and Wösten, 2017). In this fungus, apical compartments are self-sustaining in growth. This was concluded from the finding that the growth rate in these compartments remains unaffected when they are mechanically detached from the rest of the hypha. Interestingly, the first subapical compartments (up to eight) function as a backup system for growth by forming new branches upon damage of the apical compartment (Tegelaar and Wösten, 2017). This backup system appears crucial in nature considering the fact that fungal colonies continuously explore substrates that may locally be hostile for growth. By forming sub-apical branches that do not grow parallel to the damaged hypha, but rather grow away from it, the organism can avoid a second confrontation with the source of damage (i.e. a competing organism or a nutrient void zone).

\subsection{Multilevel heterogeneity in liquid environments}

Fungi and streptomycetes produce respectively about $42 \%$ and $32 \%$ of the more than 23,000 known microbial bio-active compounds (i.e. compounds with antifungal, antibacterial, antiviral, antitumor, cytotoxic and immunosuppressive activity) (Barka et al., 2016; Hopwood, 2007; Lazzarini et al., 2000). They also possess a remarkable capacity to produce and efficiently secrete various hydrolytic enzymes that allow them to degrade almost any naturally occurring polymer (Anné et al., 2012; Hoffmeister and Keller, 2007). The ability of streptomycetes and filamentous fungi to produce this treasure trove of commercially- valuable compounds and enzymes has led to their large-scale industrial exploitation (Hopwood, 2007). In industry, microbes are typically grown in large bioreactors. This choice is dictated by the fact that these systems provide the most reproducible and efficient manner to obtain high growth and production rates, which are achieved through parametric control and the efficient provision of nutrients and oxygen to cells. Notably, the continuous and often vigorous mixing of the culture medium creates a more homogenous environment for the mycelia when compared to growth on solid substrates. Yet, gradients can still exist, especially with the large volumes that are characteristic of industrial fermentation processes. Notably, heterogeneity in process parameters (e.g. $\mathrm{pH}$, temperature, concentration of biomass and nutrients) can result in physiological heterogeneity and the occurrence of culture segregation in a number of microorganisms (Delvigne et al., 2009; Takors, 2012). In addition, fluctuating aeration regimes have been shown to decrease product formation both in streptomycetes and filamentous fungi (Larsson and Enfors, 1998; Yegneswaran et al., 1991).

The mode-of-growth of streptomycetes and filamentous fungi in bioreactors is markedly different when compared to solid substrates. Depending on the strain and culture setup, the mycelium of these filamentous microbes can display a range of different morphologies (Braun and Vecht-Lifshitz, 1991; Tresner et al., 1967; van Dissel et al., 2014). Many species, among which the industrial cell factories S. lividans and A. niger, can form dense mycelial particles called pellets (also micro-colonies for filamentous fungi). These particles can have a diameter larger than $1 \mathrm{~mm}$, with the pellets formed by Aspergillus being generally larger than those of streptomycetes (van Veluw et al., 2012; van Veluw et al., 2013). This mode-of-growth promotes physiological heterogeneity due to the differential diffusion of oxygen, nutrients and metabolic (by)products. One of the consequences of growth in dense 
pellets is that hyphae in the central part of these particles are typically starved due to the limited availability of oxygen and nutrients (Bizukojc and Gonciarz, 2015; Clark, 1962; Driouch et al., 2012; Gerlach et al., 1998; Wittier et al., 1986). The impact of nutrient and oxygen limitation on pelleted growth is also evident in other multicellular communities (e.g. biofilms) formed by single or multiple species (Kragh et al., 2016; von Ohle et al., 2010). The interplay between environmentallydetermined heterogeneity and actively regulated development is however still obscure. In this context, it is interesting to mention that cells residing within a biofilm structure have been found to be more heterogeneous as opposed to planktonic cells. In experiments with Pseudomonas aeruginosa, phenotypical variation was found to arise when cells were cultured in the form of biofilms. Although the factors inducing this heterogeneity are unknown, a recombination-dependent system was found to provide the source of genotypic variation leading to the observed phenotypes. Furthermore, cells that had gained mutations after residing in biofilms displayed more variation in swimming capability and enhanced resistance to a number of environmental insults including oxidative stress and exposure to antimicrobials (Boles et al., 2004).

In addition to differential responses to environmental cues, deterministic choices may also stimulate heterogeneous growth in liquid environments. Most Streptomyces strains do not sporulate in liquidgrown cultures; nevertheless, a certain degree of developmental and physiological heterogeneity is evident throughout the mycelium. As on solid substrates, the mycelial structure changes throughout growth, and is characterized by frequent compartmentalization at early time points (Manteca et al., 2008; Manteca et al., 2005a). Following a round of cellular dismantling, a multinucleated mycelium is established which contains fewer compartments. By this time, the production of antibiotics becomes noticeable. Contrary to growth on solid substrates, neither is this newly established mycelium dismantled, nor does sporulation occur. Gene expression profiling indicated however, that the majority of transcripts identified on solid substrates are also present in liquid-grown cultures, including activators of secondary metabolism and development (Yagüe et al., 2014). Together, these findings indicate that heterogeneity is common in liquid-grown streptomycetes.

Another form of heterogeneity was discovered in pellet-forming streptomycetes and fungi by analyzing large numbers of pellets with a flow cytometry approach. This revealed that cultures of both filamentous fungi and streptomycetes contain at least two normally distributed populations of pellets that differ in size (de Bekker et al., 2011b; van Veluw et al., 2012; van Veluw et al., 2013) (Fig. 2). This heterogeneity is observed in a range of strains and growth media, suggesting that it is inherent to the mode-of-growth of these organisms. Interestingly, gene expression in micro-colonies can also be described as a bimodal distribution. For instance, two populations of $A$. niger microcolonies exist in submerged cultures; one highly and one lowly expressing the glucoamylase gene (de Bekker et al., 2011b). In Streptomyces coelicolor, 37 proteins were found to be significantly different in abundance between the populations of large and small pellets. While 17 of these proteins are significantly overrepresented in large pellets as opposed to the small ones, 20 are significantly underrepresented (van Veluw et al., 2012). Several of the proteins that are over- or underrepresented could be assigned to specific functional classes, with a number of stress-related proteins being overrepresented in the population of large pellets. The protein that is most strongly enhanced (around 30-fold) in the larger pellets is EgtD, a protein involved in the biosynthesis of the rare amino acid ergothioneine. The synthesis of this molecule is rare in microbes, with a higher incidence in actinobacteria (including mycobacteria) and filamentous fungi. The role of ergothioneine in these organisms is still obscure, but it has antioxidant properties, which suggests that it might be involved in a stress-response mechanism. Other stress-related proteins being overrepresented in the population of large pellets include polypeptides encoded by genes in the $o s d R$ locus, including the gene for the universal stress protein (USP)
(SCO0200) (van Veluw et al., 2012). Recent studies revealed that osdR controls development and oxidative stress, and is functionally similar to DosR, the oxygen-sensitive dormancy response regulator in Mycobacterium tuberculosis (Urem et al., 2016). It is interesting to mention that the classes of genes being differently expressed in Streptomyces pellets are known to be subject to transcriptional noise in other microbes (see above).

\section{Mechanisms underlying heterogeneity in filamentous microbes}

\subsection{Inter-hyphal and inter-compartmental heterogeneity}

The hyphae of streptomycetes and the higher fungi (i.e. ascomycetes and basidiomycetes) are compartmentalized by cross-walls (also called septa). In streptomycetes, some of these cross-walls have channels, which potentially would allow streaming of cytoplasmic content, although this has never been demonstrated directly (Bleichrodt et al., 2012; Celler et al., 2016; Jakimowicz and van Wezel, 2012; Yagüe et al., 2016). In addition to cross-walls, recent work has shown that extended membranous structures are able to spatially and functionally organize the vegetative mycelium of streptomycetes (Celler et al., 2016; Yaguie et al., 2016) (Fig. 3). These cross-membranes are responsible for the formation of the alternating pattern of viable and dead hyphae in the early MI mycelium and also block the diffusion of cytoplasmic proteins in $29 \%$ of the cases. Cross-membranes might thus maintain heterogeneity between compartments of the same cell by preventing molecules to mix by diffusion or streaming.

Septa of filamentous fungi consist of invaginations of the cell wall that are ligned with plasma membrane. Septa have a central pore of 50-500 nm (Moore and McAlear, 1962; Shatkin and Tatum, 1959) that allows streaming of cytosol and even organelles, thus enabling cytoplasmic mixing throughout the mycelium. Yet, the pores of Aspergillus can be reversibly opened and closed by peroxisome-derived organelles called Woronin bodies (Bleichrodt et al., 2012) (Fig. 3). The absence of Woronin bodies prevents septal closure, thereby abolishing the possibility to maintain long-term heterogeneity in cytosolic composition between neighboring compartments and/or hyphae (Bleichrodt et al., 2012). It should be noted that even an open septum can maintain differences in cytosolic composition due to differential gene expression. In this case, however, heterogeneity can be only maintained in a minutes time-frame. Yet, this may be sufficient for some developmental processes to be initiated (Bleichrodt et al., 2015a; Bleichrodt et al., 2015b). Together, an arrest or reduction in cytoplasmic streaming between adjacent compartments can maintain long term heterogeneity in RNA and protein composition. Notably, the plugging of septa via Woronin bodies has no effect on inter-compartmental transport of glucose (Bleichrodt et al., 2015b). This is explained by the fact that Aspergillus uses permeases to enable the selective transport of metabolites. In this scenario, inter-compartmental and inter-hyphal heterogeneous distributions are only obtained for those components that cannot cross the selective plasma membrane of septa (e.g. large proteins, ribosomes, organelles, and metabolites that lack a permease in the plasma membrane lining the septal cross wall).

\subsection{Inter-pellet heterogeneity}

The aggregation of distinct particles is a driving factor for generating size heterogeneity between pellets. Aggregation in streptomycetes is mediated by extracellular glycans on the surface of germlings and young mycelia (Zacchetti et al., 2016). These glycans are produced under control of the $c s l A / g l x A$ operon and the mat cluster (Chaplin et al., 2015; de Jong et al., 2009; Petrus et al., 2016; van Dissel et al., 2015; Xu et al., 2008). The structure of the glycan produced by CslA and GlxA is still unknown, while the polymer produced by the Mat proteins is poly- $\beta$ (1,6)- $N$-acetylglucosamine (PNAG) (van Dissel et al., 2018). Abolishing the formation of these glycans yields particles whose size is no longer 


\section{Aspergillus hypha}

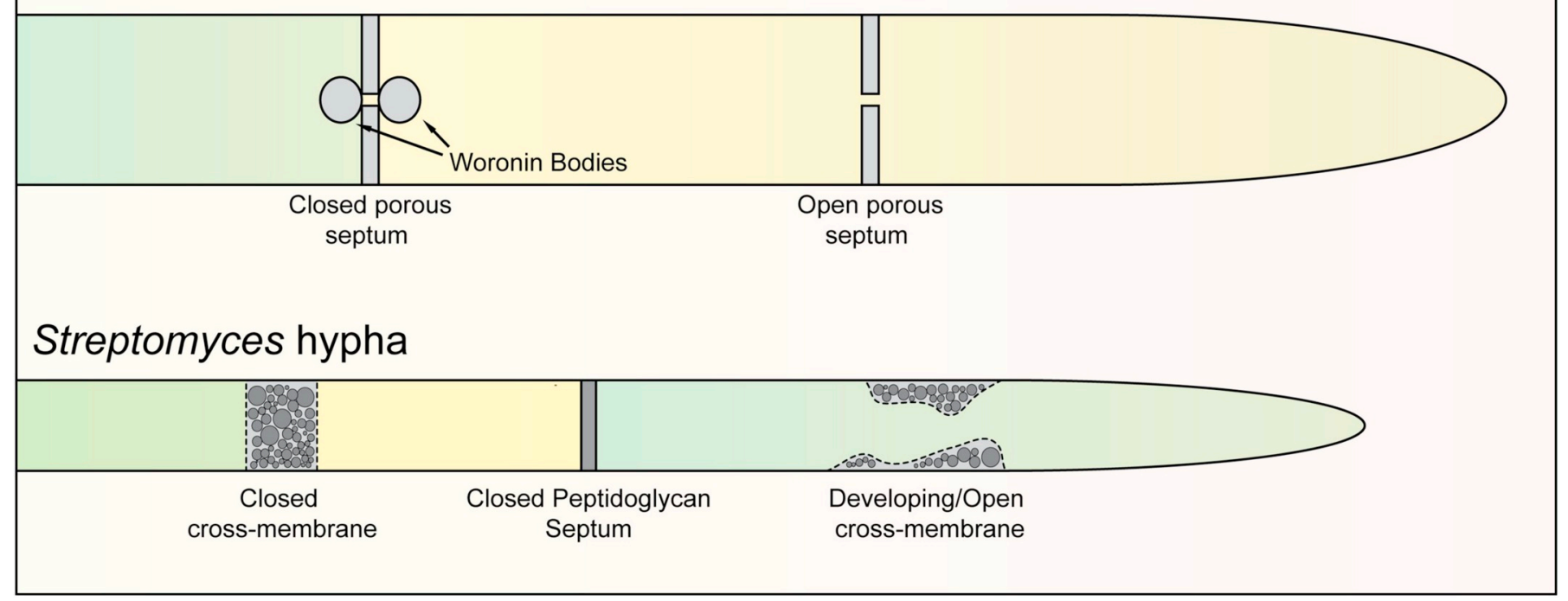

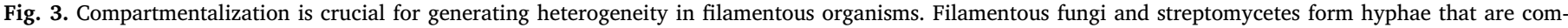

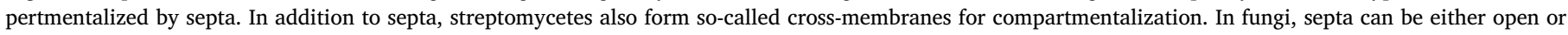

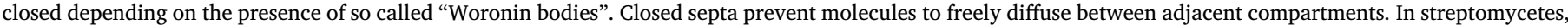
extended cross-membrane structures prevent cytoplasmic streaming, thereby generating heterogeneity within filaments.

bimodally distributed and that are hence more homogeneous in size. Also, in filamentous fungi aggregation is a critical factor in generating size heterogeneity. In this case, aggregation is a two-step process. The first phase involves the aggregation of ungerminated spores and is followed by a second aggregation phase that occurs between germlings (Grimm et al., 2004). Mutants of $A$. niger affected in the formation of spore-associated pigments yield more homogeneously-distributed pellets (van Veluw et al., 2013). The underlying mechanism is not known but one wonders whether filamentous microbes make use of size heterogeneity to optimally adapt to the environment. Micro-colonies of different size might experience environmental stimuli differently and may thus differently react to these cues.

\section{Parallels and differences between unicellular and multicellular systems}

The cellular architecture of filamentous microbes generates layers of complexity that are rarely observed in unicellular species and that result in the multiscale heterogeneity discussed in this review. As a result of this complexity, some of the well-described aspects of phenotypic heterogeneity have not yet been characterized in filamentous microbes. Mechanisms analogous to those reported in unicellular systems, such as intrinsic noise in transcription and translation, are inherent to the behaviour of their machinery, and therefore a likely source of heterogeneity in any biological system, including filamentous microbes. Uniquely for filamentous microorganisms is the syncytial nature of mycelia. The distribution of DNA (i.e. nuclei in fungi or chromosomes in bacteria) may not only differ between compartments, but also within compartments. This, in turn, would result in some regions possessing more copies of a given gene. Such dosage effects are known to bear a profound effect on decision making in a number of cellular systems (Chai et al., 2011; Narula et al., 2015; Slager et al., 2014; Soler-Bistue et al., 2015; Veening et al., 2006). Additionally, the positioning of nuclei can also result in differential gene expression within single compartments. For instance, paired nuclei in compartments of the mushroom-forming fungus Schizophyllum commune can migrate away from each other, resulting in changes in gene expression (Schuurs et al., 1998). Thus, while some of the mechanisms involved in generating heterogeneity could be similar between filamentous and unicellular microbes, some factors (e.g. the presence of inter-compartmental streaming and multinucleate compartments) are probably unique for filamentous microorganisms.

Differences in the mechanisms through which heterogeneities arise might also differ between filamentous bacteria and filamentous fungi. Not only is gene regulation different between bacteria and fungi, also their sizes differ. The cellular volume of a fungal filament is roughly 100 times larger than that of a streptomycete given the 10-fold larger diameter of a fungal hypha. This may affect the concentration of various intracellular species. As a consequence, noise dynamics might differ in these systems. However, no quantitative data of abundance of molecules exist that cause heterogeneity in filamentous microbes, thus hindering a direct comparison.

One of the most remarkable aspects of microbial phenotypic heterogeneity is its beneficial role in increasing population fitness in the face of changing environmental conditions (see Section 2). It is currently unknown whether this is also true for filamentous microbes. Mycelial heterogeneity may be beneficial in terrestrial soils, where spatial and temporal variations exist in for instance the availability of nutrients and oxygen, temperature, $\mathrm{pH}$, and the amount of growth-inhibiting compounds (Stoyan et al., 2000). Considering the saprophytic lifestyle of most filamentous microbes and the close proximity of hyphae within a colony, one would predict a benefit for segregating functions across the colony. This would be particularly useful for acquiring nutrients or secreting costly compounds that ultimately become available to all surrounding hyphae. In this scenario, inter-hyphal heterogeneities in the secretion of enzymes (as those observed in $A$. niger) might very well reflect a division of labour strategy, in that only a subset of hyphae commit to the production of extracellular hydrolases, thereby liberating nutrients that can be taken up by both producing and non-producing hyphae. Another example where heterogeneity could provide fitness benefits to the colony is in the production of antibiotics. However, this awaits further experimental evidence. 


\section{Conclusions and future perspectives}

Striking parallels exist between filamentous fungi and actinomycetes with respect to morphology, heterogeneity and the architecture of mycelia. Despite the increasing number of studies, we have only started to dissect the mechanisms underlying heterogeneity in these organisms. While cytoplasmic streaming in the fungal mycelium has been known for many decades, it has only recently been reported in streptomycetes (Celler et al., 2016). Selective blocking of this process, either via Woronin bodies in fungi or membranous structures in actinomycetes, leads to physiological differences between adjacent compartments and zones of the colony. One of the outstanding questions to address is how the external and internal signals are processed and translated into changes in cytoplasmic streaming and phenotypic heterogeneity. We believe that the developments in the field of microscopy will enable us to obtain unprecedented insight into the molecular functioning of these compartment-separating structures within hyphae.

In this review we have described the different forms of heterogeneity that have been reported in filamentous fungi and streptomycetes. Interestingly, apart from inter-colony, inter-zonal, inter-hyphal and inter-compartmental heterogeneity one may expect the existence of intra-compartmental heterogeneity. Such heterogeneity may be promoted by increasing the compartmental length and reducing the number of nuclei (fungi) or chromosomes (filamentous bacteria). Alternatively, RNAs and pathways that determine the fate of RNA could be spatially and temporally localized in subcellular compartments. More knowledge about the dynamics of nucleic acids in filaments is thus of utmost importance to better our understanding of heterogeneity.

While it is evident that heterogeneity is beneficial to filamentous microbes in natural environments, this feature is undesirable in industry for two reasons. First, heterogeneity decreases controllability of the fermentation process, and secondly, several lines of evidence indicate that morphology and specific productivity appear to be tightly coupled. For instance, production performance can be increased by reducing morphological heterogeneity (size distribution of pellets) in Streptomyces cultures (van Dissel et al., 2015; van Wezel et al., 2006; Wang et al., 2017; Wardell et al., 2002). Generally speaking, smaller micro-colonies are preferable for the production of enzymes, while bigger ones are better suited for the production of antibiotics (van Dissel et al., 2014). Promoting increased septation in S. lividans results in a reduced pellet size and in turn in increased enzyme secretion (van Wezel et al., 2006). Interfering with mycelial aggregation also results in smaller mycelial particles and increased protein secretion (van Dissel et al., 2015). While some of these phenotypes have solely been explained as the result of the increased growth rates of smaller particles, part of the increased production may be due to the reduced size heterogeneity. Likewise, increased homogeneity could also stimulate antibiotic production, given that mutants of Saccharopolyspora erythraea that on average form larger pellets than the parental strain also produce more erythromycin (Wardell et al., 2002). At the same time, we cannot exclude that hyphae within mycelia of liquid-grown cultures differentiate to fulfil specific functions. In this case, heterogeneous cultures may be more productive. In light of this, it is critical to better understand the molecular mechanisms underlying heterogeneity in filamentous organisms, a quest that might be facilitated in the near future by the increasing power of next-generation sequencing technologies applied at the single cell level and the further advancement of high-end microscopy. Only once these mechanisms will have been unraveled, will we be able to tackle heterogeneity in non-natural settings, with the alluring prospect of enhanced production performances in the biotech sector.

\section{Acknowledgements}

Work in the Claessen lab is supported by a VIDI grant (12957) from the Netherlands Organisation for Scientific Research.

\section{References}

Ackermann, M., 2015. A functional perspective on phenotypic heterogeneity in microorganisms. Nat. Rev. Microbiol. 13 (8), 497-508.

Adams, D.G., 2000. Heterocyst formation in cyanobacteria. Curr. Opin. Microbiol. 3 (6), 618-624.

Anné, J., Maldonado, B., Van Impe, J., Van Mellaert, L., Bernaerts, K., 2012. Recombinant protein production and streptomycetes. J. Biotechnol. 158 (4), 159-167.

Arnoldini, M., Vizcarra, I.A., Peña-Miller, R., Stocker, N., Diard, M., Vogel, V., Beardmore R.E., Hardt, W.D., Ackermann, M., 2014. Bistable expression of virulence genes in Salmonella leads to the formation of an antibiotic-tolerant subpopulation. PLoS Biol. 12 (8), e1001928.

Avery, S.V., 2006. Microbial cell individuality and the underlying sources of heterogeneity. Nat. Rev. Microbiol. 4 (8), 577-587.

Avraham, N., Soifer, I., Carmi, M., Barkai, N., 2013. Increasing population growth by asymmetric segregation of a limiting resource during cell division. Mol. Syst. Biol. 9 , 656.

Balaban, N.Q., Merrin, J., Chait, R., Kowalik, L., Leibler, S., 2004. Bacterial persistence as a phenotypic switch. Science 305 (5690), 1622-1625.

Barka, E.A., Vatsa, P., Sanchez, L., Gaveau-Vaillant, N., Jacquard, C., Klenk, H.P., Clément, C., Ouhdouch, Y., van Wezel, G.P., 2016. Taxonomy, physiology, and natural products of Actinobacteria. Microbiol. Mol. Biol. Rev. 80 (1), 1-43.

Bérdy, J., 2005. Bioactive microbial metabolites. J. Antibiot. (Tokyo) 58 (1), 1-26.

Berleman, J.E., Chumley, T., Cheung, P., Kirby, J.R., 2006. Rippling is a predatory behavior in Myxococcus xanthus. J. Bacteriol. 188 (16), 5888-5895.

Berman-Frank, I., Lundgren, P., Chen, Y.B., Küpper, H., Kolber, Z., Bergman, B., Falkowski, P., 2001. Segregation of nitrogen fixation and oxygenic photosynthesis in the marine cyanobacterium Trichodesmium. Science 294 (5546), 1534-1537.

Berthoumieux, S., de Jong, H., Baptist, G., Pinel, C., Ranquet, C., Ropers, D., Geiselmann, J., 2013. Shared control of gene expression in bacteria by transcription factors and global physiology of the cell. Mol. Syst. Biol. 9, 634.

Binder, D., Drepper, T., Jaeger, K.E., Delvigne, F., Wiechert, W., Kohlheyer, D., Grünberger, A., 2017. Homogenizing bacterial cell factories: analysis and engineering of phenotypic heterogeneity. Metab. Eng. 42, 145-156.

Bizukojc, M., Gonciarz, J., 2015. Influence of oxygen on lovastatin biosynthesis by Aspergillus terreus ATCC 20542 quantitatively studied on the level of individual pellets. Bioprocess Biosyst. Eng. 38 (7), 1251-1266.

Blake, W.J., Kærn, M., Cantor, C.R., Collins, J.J., 2003. Noise in eukaryotic gene ex pression. Nature 422 (6932), 633-637.

Bleichrodt, R.J., van Veluw, G.J., Recter, B., Maruyama, J., Kitamoto, K., Wösten, H.A.B., 2012. Hyphal heterogeneity in Aspergillus oryzae is the result of dynamic closure of septa by Woronin bodies. Mol. Microbiol. 86 (6), 1334-1344.

Bleichrodt, R.J., Hulsman, M., Wösten, H.A.B., Reinders, M.J.T., 2015a. Switching from a unicellular to multicellular organization in an Aspergillus niger hypha. MBio 6 (2), e00111.

Bleichrodt, R.J., Vinck, A., Read, N.D., Wösten, H.A.B., 2015b. Selective transport between heterogeneous hyphal compartments via the plasma membrane lining septal walls of Aspergillus niger. Fungal Genet. Biol. 82, 193-200.

Boles, B.R., Thoendel, M., Singh, P.K., 2004. Self-generated diversity produces "insurance effects" in biofilm communities. Proc. Natl. Acad. Sci. U. S. A. 101 (47), $16630-16635$.

Borkovich, K.A., Ebbole, D.J., 2010. Cellular and Molecular Biology of Filamentous Fungi. ASM Press.

Braun, S., Vecht-Lifshitz, S.E., 1991. Mycelial morphology and metabolite production. Trends Biotechnol. 9 (1), 63-68.

Brehm-Stecher, B.F., Johnson, E.A., 2004. Single-cell microbiology: tools, technologies, and applications. Microbiol. Mol. Biol. Rev. 68 (3), 538-559.

Cai, L., Friedman, N., Xie, X.S., 2006. Stochastic protein expression in individual cells at the single molecule level. Nature 440 (7082), 358-362.

Celler, K., Koning, R.I., Willemse, J., Koster, A.J., van Wezel, G.P., 2016. Cross-membranes orchestrate compartmentalization and morphogenesis in Streptomyces. Nat. Commun. 7, 11836.

Chai, Y.R., Norman, T., Kolter, R., Losick, R., 2011. Evidence that metabolism and chromosome copy number control mutually exclusive cell fates in Bacillus subtilis. EMBO J. 30 (7), 1402-1413.

Chaplin, A.K., Petrus, M.L.C., Mangiameli, G., Hough, M.A., Svistunenko, D.A., Nicholls, P., Claessen, D., Vijgenboom, E., Worrall, J.A.R., 2015. GlxA is a new structural member of the radical copper oxidase family and is required for glycan deposition at hyphal tips and morphogenesis of Streptomyces lividans. Biochem. J. 469 (3), 433-444.

Chastanet, A., Vitkup, D., Yuan, G.C., Norman, T.M., Liu, J.S., Losick, R.M., 2010. Broadly heterogeneous activation of the master regulator for sporulation in Bacillus subtilis. Proc. Natl. Acad. Sci. U. S. A. 107 (18), 8486-8491.

Chater, K.F., 1998. Taking a genetic scalpel to the Streptomyces colony. Microbiology-sgm 144, 1465-1478.

Claessen, D., Rozen, D.E., Kuipers, O.P., Søgaard-Andersen, L., van Wezel, G.P., 2014 Bacterial solutions to multicellularity: a tale of biofilms, filaments and fruiting bodies. Nat. Rev. Microbiol. 12 (2), 115-124.

Clark, D.S., 1962. Submerged citric acid fermentation of ferrocyanide-treated beet molasses: morphology of pellets of Aspergillus niger. Can. J. Microbiol. 8, 133-136.

Claudi, B., Spröte, P., Chirkova, A., Personnic, N., Zankl, J., Schürmann, N., Schmidt, A., Bumann, D., 2014. Phenotypic variation of Salmonella in host tissues delays eradication by antimicrobial chemotherapy. Cell 158 (4), 722-733.

Davis, K.M., Isberg, R.R., 2016. Defining heterogeneity within bacterial populations via single cell approaches. BioEssays 38 (8), 782-790. 
de Bekker, C., Bruning, O., Jonker, M.J., Breit, T.M., Wösten, H.A.B., 2011a. Single cell transcriptomics of neighboring hyphae of Aspergillus niger. Genome Biol. 12 (8), R71.

de Bekker, C., van Veluw, G.J., Vinck, A., Wiebenga, L.A., Wösten, H.A.B., 2011b. Heterogeneity of Aspergillus niger microcolonies in liquid shaken cultures. Appl. Environ. Microbiol. 77 (4), 1263-1267.

de Jong, W., Wösten, H.A.B., Dijkhuizen, L., Claessen, D., 2009. Attachment of Streptomyces coelicolor is mediated by amyloidal fimbriae that are anchored to the cell surface via cellulose. Mol. Microbiol. 73 (6), 1128-1140.

de Lorenzo, V., Sekowska, A., Danchin, A., 2015. Chemical reactivity drives spatiotemporal organisation of bacterial metabolism. FEMS Microbiol. Rev. 39 (1), 96-119.

Delvigne, F., Boxus, M., Ingels, S., Thonart, P., 2009. Bioreactor mixing efficiency modulates the activity of a prpoS::GFP reporter gene in E. coli. Microb. Cell Factories $8,15$.

Delvigne, F., Baert, J., Sassi, H., Fickers, P., Grunberger, A., Dusny, C., 2017. Taking control over microbial populations: current approaches for exploiting biological noise in bioprocesses. Biotechnol. J. 12 (7).

Diard, M., Garcia, V., Maier, L., Remus-Emsermann, M.N., Regoes, R.R., Ackermann, M., Hardt, W.D., 2013. Stabilization of cooperative virulence by the expression of an avirulent phenotype. Nature 494 (7437), 353-356.

Dörr, T., Vulić, M., Lewis, K., 2010. Ciprofloxacin causes persister formation by inducing the TisB toxin in Escherichia coli. PLoS Biol. 8 (2), e1000317.

Driouch, H., Hänsch, R., Wucherpfennig, T., Krull, R., Wittmann, C., 2012. Improved enzyme production by bio-pellets of Aspergillus niger: targeted morphology engineering using titanate microparticles. Biotechnol. Bioeng. 109 (2), 462-471.

Elowitz, M.B., Levine, A.J., Siggia, E.D., Swain, P.S., 2002. Stochastic gene expression in a single cell. Science 297 (5584), 1183-1186.

Errington, J., 2003. Regulation of endospore formation in Bacillus subtilis. Nat. Rev. Microbiol. 1 (2), 117-126.

Flärdh, K., 2010. Cell polarity and the control of apical growth in Streptomyces. Curr Opin. Microbiol. 13 (6), 758-765.

Gerlach, S.R., Siedenberg, D., Gerlach, D., Schügerl, K., Giuseppin, M.L.F., Hunik, J., 1998. Influence of reactor systems on the morphology of Aspergillus awamori. Application of neural network and cluster analysis for characterization of fungal morphology. Process Biochem. 33 (6), 601-615.

Golding, I., Paulsson, J., Zawilski, S.M., Cox, E.C., 2005. Real-time kinetics of gene activity in individual bacteria. Cell 123 (6), 1025-1036.

Goodfellow, M., Mordarski, M., Williams, S.T., 1983. The Biology of the Actinomycetes. Academic Press, London.

Grimbergen, A.J., Siebring, J., Solopova, A., Kuipers, O.P., 2015. Microbial bet-hedging: the power of being different. Curr. Opin. Microbiol. 25, 67-72.

Grimm, L.H., Kelly, S., Hengstler, J., Göbel, A., Krull, R., Hempel, D.C., 2004. Kinetic studies on the aggregation of Aspergillus niger conidia. Biotechnol. Bioeng. 87 (2), 213-218.

Grünberger, A., Schöler, K., Probst, C., Wiechert, W., Noack, S., Kohlheyer, D., 2013. Simple microfluidics for complex organisms: a microfluidic chip system for growth and morphogenesis studies of filamentous fungi. In: 17th International Conference on Miniaturized Systems for Chemistry and Life Sciences, Microtas 2013. 2, pp. 1273-1275.

Grunberger, A., Wiechert, W., Kohlheyer, D., 2014. Single-cell microfluidics: opportunity for bioprocess development. Curr. Opin. Biotechnol. 29, 15-23.

He, C., Fong, L.G., Young, S.G., Jiang, H., 2017. NanoSIMS imaging: an approach for visualizing and quantifying lipids in cells and tissues. J. Investig. Med. 65 (3), 669-672.

Helaine, S., Cheverton, A.M., Watson, K.G., Faure, L.M., Matthews, S.A., Holden, D.W., 2014. Internalization of Salmonella by macrophages induces formation of nonreplicating persisters. Science 343 (6167), 204-208.

Henson, M.A., 2003. Dynamic modeling of microbial cell populations. Curr. Opin. Biotechnol. 14 (5), 460-467.

Higgins, D., Dworkin, J., 2012. Recent progress in Bacillus subtilis sporulation. FEMS Microbiol. Rev. 36 (1), 131-148.

Hoffmeister, D., Keller, N.P., 2007. Natural products of filamentous fungi: enzymes, genes, and their regulation. Nat. Prod. Rep. 24 (2), 393-416.

Hol, F.J.H., Dekker, C., 2014. Zooming in to see the bigger picture: microfluidic and nanofabrication tools to study bacteria. Science 346 (6208), 438.

Hopwood, D.A., 2007. Streptomyces in Nature and Medicine: The Antibiotic Makers. Oxford University Press, USA, New York.

Jacob, F., Monod, J., 1961. Genetic regulatory mechanisms in the synthesis of proteins. J. Mol. Biol. 3, 318-356.

Jakimowicz, D., van Wezel, G.P., 2012. Cell division and DNA segregation in Streptomyces: how to build a septum in the middle of nowhere? Mol. Microbiol. 85 (3), 393-404.

Jia, C., Qian, M., Kang, Y., Jiang, D., 2014. Modeling stochastic phenotype switching and bet-hedging in bacteria: stochastic nonlinear dynamics and critical state identification. Quant. Biol. 2 (3), 110-125.

Johnson, P.J.T., Levin, B.R., 2013. Pharmacodynamics, population dynamics, and the evolution of persistence in Staphylococcus aureus. PLoS Genet. 9 (1), e1003123.

Johnson, D.R., Goldschmidt, F., Lilja, E.E., Ackermann, M., 2012. Metabolic specialization and the assembly of microbial communities. ISME J. 6 (11), 1985-1991.

Jones, S.E., Elliot, M.A., 2017. Streptomyces exploration: competition, volatile communication and new bacterial behaviours. Trends Microbiol. 25 (7), 522-531.

Jones, S.E., Ho, L., Rees, C.A., Hill, J.E., Nodwell, J.R., Elliot, M.A., 2017. Streptomyces exploration is triggered by fungal interactions and volatile signals. eLife 6, e21738.

Kiviet, D.J., Nghe, P., Walker, N., Boulineau, S., Sunderlikova, V., Tans, S.J., 2014. Stochasticity of metabolism and growth at the single-cell level. Nature 514 (7522), 376-379.

Klumpp, S., Hwa, T., 2014. Bacterial growth: global effects on gene expression, growth feedback and proteome partition. Curr. Opin. Biotechnol. 28, 96-102.

Kotte, O., Volkmer, B., Radzikowski, J.L., Heinemann, M., 2014. Phenotypic bistability in Escherichia coli's central carbon metabolism. Mol. Syst. Biol. 10, 736.

Kragh, K.N., Hutchison, J.B., Melaugh, G., Rodesney, C., Roberts, A.E., Irie, Y., Jensen, P.Ø., Diggle, S.P., Allen, R.J., Gordon, V., Bjarnsholt, T., 2016. Role of multicellular aggregates in biofilm formation. MBio 7 (2), e00237.

Krijgsheld, P., Altelaar, A.F., Post, H., Ringrose, J.H., Müller, W.H., Heck, A.J.R., Wösten, H.A.B., 2012. Spatially resolving the secretome within the mycelium of the cell factory Aspergillus niger. J. Proteome Res. 11 (5), 2807-2818.

Krijgsheld, P., Bleichrodt, R., van Veluw, G.J., Wang, F., Muller, W.H., Dijksterhuis, J., Wösten, H.A.B., 2013a. Development in Aspergillus. Stud. Mycol. 74, 1-29.

Krijgsheld, P., Nitsche, B.M., Post, H., Levin, A.M., Müller, W.H., Heck, A.J.R., Ram, A.F.J., Altelaar, A.F., Wösten, H.A.B., 2013b. Deletion of $f l b A$ results in increased secretome complexity and reduced secretion heterogeneity in colonies of Aspergillus niger. J. Proteome Res. 12 (4), 1808-1819.

Kues, U., Liu, Y., 2000. Fruiting body production in basidiomycetes. Appl. Microbiol. Biotechnol. 54 (2), 141-152.

Kumar, K., Mella-Herrera, R.A., Golden, J.W., 2010. Cyanobacterial heterocysts. Cold Spring Harb. Perspect. Biol. 2 (4), a000315.

Larsson, G., Enfors, S.O., 1998. Studies of insufficient mixing in bioreactors: effects of limiting oxygen concentrations and short term oxygen starvation on Penicillium chrysogenum. Bioprocess Eng. 3 (3), 123-127.

Lazzarini, A., Cavaletti, L., Toppo, G., Marinelli, F., 2000. Rare genera of actinomycetes as potential producers of new antibiotics. Antonie Van Leeuwenhoek 78 (3-4), 399-405.

Levin, A.M., de Vries, R.P., Conesa, A., de Bekker, C., Talon, M., Menke, H.H., van Peij, N.N.M.E., Wösten, H.A.B., 2007. Spatial differentiation in the vegetative mycelium of Aspergillus niger. Eukaryot. Cell 6 (12), 2311-2322.

Levine, J.H., Fontes, M.E., Dworkin, J., Elowitz, M.B., 2012. Pulsed feedback defers cellular differentiation. PLoS Biol. 10 (1), e1001252.

Levine, J.H., Lin, Y., Elowitz, M.B., 2013. Functional roles of pulsing in genetic circuits. Science 342 (6163), 1193-1200.

Levy, S.F., Ziv, N., Siegal, M.L., 2012. Bet hedging in yeast by heterogeneous, age-correlated expression of a stress protectant. PLoS Biol. 10 (5), e1001325.

Locke, J.C., Young, J.W., Fontes, M., Hernandez Jimenez, M.J., Elowitz, M.B., 2011 Stochastic pulse regulation in bacterial stress response. Science 334 (6054), 366-369.

Lu, C., Brauer, M.J., Botstein, D., 2009. Slow growth induces heat-shock resistance in normal and respiratory-deficient yeast. Mol. Biol. Cell 20 (3), 891-903.

Maamar, H., Raj, A., Dubnau, D., 2007. Noise in gene expression determines cell fate in Bacillus subtilis. Science 317 (5837), 526-529.

Manina, G., Dhar, N., McKinney, J.D., 2015. Stress and host immunity amplify Mycobacterium tuberculosis phenotypic heterogeneity and induce nongrowing metabolically active forms. Cell Host Microbe 17 (1), 32-46.

Manteca, A., Fernandez, M., Sanchez, J., 2005a. A death round affecting a young compartmentalized mycelium precedes aerial mycelium dismantling in confluent surface cultures of Streptomyces antibioticus. Microbiology 151, 3689-3697.

Manteca, A., Fernandez, M., Sanchez, J., 2005b. Mycelium development in Streptomyces antibioticus ATCC11891 occurs in an orderly pattern which determines multiphase growth curves. BMC Microbiol. 5, 51.

Manteca, A., Fernandez, M., Sanchez, J., 2006. Cytological and biochemical evidence for an early cell dismantling event in surface cultures of Streptomyces antibioticus. Res. Microbiol. 157 (2), 143-152.

Manteca, A., Claessen, D., Lopez-Iglesias, C., Sanchez, J., 2007. Aerial hyphae in surface cultures of Streptomyces lividans and Streptomyces coelicolor originate from viable segments surviving an early programmed cell death event. FEMS Microbiol. Lett. 274 (1), 118-125.

Manteca, A., Alvarez, R., Salazar, N., Yagüe, P., Sanchez, J., 2008. Mycelium differ entiation and antibiotic production in submerged cultures of Streptomyces coelicolor. Appl. Environ. Microbiol. 74 (12), 3877-3886.

Manteca, A., Sanchez, J., Jung, H.R., Schwämmle, V., Jensen, O.N., 2010. Quantitative proteomic analysis of Streptomyces coelicolor development demonstrates that onset of secondary metabolism coincides with hyphae differentiation. Mol. Cell. Proteomics 9 (7), 1423-1436.

Meister, A., Du, C., Li, Y.H., Wong, W.H., 2014. Modeling stochastic noise in gene regulatory systems. Quant. Biol. 2 (1), 1-29.

Mitsui, A., Kumazawa, S., Takahashi, A., Ikemoto, H., Cao, S., Arai, T., 1986. Strategy by which nitrogen-fixing unicellular cyanobacteria grow photoautotrophically. Nature 323 (6090), 720-722.

Monod, J., 1949. The growth of bacterial cultures. Annu. Rev. Microbiol. 3, 371-394.

Moore, R.T., McAlear, J.H., 1962. Fine structure of mycota. 7. Observations on septa of ascomycetes and basidiomycetes. Am. J. Bot. 49 (1), 86.

Moukha, S.M., Wösten, H.A.B., Asther, M., Wessels, J.G.H., 1993a. In situ localization of the secretion of lignin peroxidases in colonies of Phanerochaete chrysosporium using a sandwiched mode of culture. J. Gen. Microbiol. 139, 969-978.

Moukha, S.M., Wösten, H.A.B., Mylius, E.J., Asther, M., Wessels, J.G.H., 1993b. Spatial and temporal accumulation of mRNAs encoding two common lignin peroxidases in Phanerochaete chrysosporium. J. Bacteriol. 175 (11), 3672-3678.

Mulcahy, L.R., Burns, J.L., Lory, S., Lewis, K., 2010. Emergence of Pseudomonas aeruginosa strains producing high levels of persister cells in patients with cystic fibrosis. J. Bacteriol. 192 (23), 6191-6199.

Nariya, H., Inouye, M., 2008. MazF, an mRNA interferase, mediates programmed cell death during multicellular Myxococcus development. Cell 132 (1), 55-66.

Narula, J., Kuchina, A., Lee, D.Y.D., Fujita, M., Suel, G.M., Igoshin, O.A., 2015. Chromosomal arrangement of phosphorelay genes couples sporulation and DNA replication. Cell 162 (2), 328-337.

Newman, J.R., Ghaemmaghami, S., Ihmels, J., Breslow, D.K., Noble, M., Derisi, J.L., 
Weissman, J.S., 2006. Single-cell proteomic analysis of S. cerevisiae reveals the architecture of biological noise. Nature 441 (7095), 840-846.

Nunez, J., Renslow, R., Cliff 3rd, J.B., Anderton, C.R., 2017. NanoSIMS for biological applications: current practices and analyses. Biointerphases 13, 3), $03 \mathrm{~B} 301$.

O'Connor, K.A., Zusman, D.R., 1991. Development in Myxococcus xanthus involves differentiation into two cell types, peripheral rods and spores. J. Bacteriol. 173 (11), 3318-3333.

Ozbudak, E.M., Thattai, M., Kurtser, I., Grossman, A.D., van Oudenaarden, A., 2002. Regulation of noise in the expression of a single gene. Nat. Genet. 31 (1), 69-73.

Papagianni, M., 2004. Fungal morphology and metabolite production in submerged mycelial processes. Biotechnol. Adv. 22 (3), 189-259.

Perez-Leblic, M.I., Reyes, F., Martinez, M.J., Lahoz, R., 1982. Cell wall degradation in the autolysis of filamentous fungi. Mycopathologia 80 (3), 147-155.

Petrus, M.L.C., van Veluw, G.J., Wösten, H.A.B., Claessen, D., 2014. Sorting of Streptomyces cell pellets using a complex parametric analyzer and sorter. J. Vis. Exp. (84), e51178.

Petrus, M.L.C., Vijgenboom, E., Chaplin, A.K., Worrall, J.A., van Wezel, G.P., Claessen, D., 2016. The DyP-type peroxidase DtpA is a Tat-substrate required for GlxA maturation and morphogenesis in Streptomyces. Open Biol. 6 (1), 150149.

Philippi, T., Seger, J., 1989. Hedging one's evolutionary bets, revisited. Trends Ecol. Evol. $4(2), 41-44$.

Pollack, J.K., Li, Z.J., Marten, M.R., 2008. Fungal mycelia show lag time before re-growth on endogenous carbon. Biotechnol. Bioeng. 100 (3), 458-465.

Reece, A., Xia, B.Z., Jiang, Z.L., Noren, B., McBride, R., Oakey, J., 2016. Microfluidic techniques for high throughput single cell analysis. Curr. Opin. Biotechnol. 40 90-96.

Reichenbach, H., 1999. The ecology of the myxobacteria. Environ. Microbiol. 1 (1), $15-21$.

Riquelme, M., 2013. Tip growth in filamentous fungi: a road trip to the apex. Annu. Rev. Microbiol. 67, 587-609.

Russell, J.R., Cabeen, M.T., Wiggins, P.A., Paulsson, J., Losick, R., 2017. Noise in a phosphorelay drives stochastic entry into sporulation in Bacillus subtilis. EMBO J. 36 (19), 2856-2869.

Schuurs, T.A., Dalstra, H.J.P., Scheer, J.M.J., Wessels, J.G.H., 1998. Positioning of nuclei in the secondary mycelium of Schizophyllum commune in relation to differential gene expression. Fungal Genet. Biol. 23 (2), 150-161.

Shatkin, A.J., Tatum, E.L., 1959. Electron microscopy of Neurospora crassa mycelia. J. Biophys. Biochem. Cytol. 6 (3), 423 \&.

Sheik, A.R., Muller, E.E., Audinot, J.N., Lebrun, L.A., Grysan, P., Guignard, C., Wilmes, P., 2016. In situ phenotypic heterogeneity among single cells of the filamentous bac terium Candidatus Microthrix parvicella. ISME J. 10 (5), 1274-1279.

Siebring, J., Elema, M.J.H., Drubi Vega, F., Kovács, Á.T., Haccou, P., Kuipers, O.P., 2014. Repeated triggering of sporulation in Bacillus subtilis selects against a protein that affects the timing of cell division. ISME J. 8 (1), 77-87.

Silander, O.K., Nikolic, N., Zaslaver, A., Bren, A., Kikoin, I., Alon, U., Ackermann, M., 2012. A genome-wide analysis of promoter-mediated phenotypic noise in Escherichia coli. PLoS Genet. 8 (1), e1002443.

Slager, J., Kjos, M., Attaiech, L., Veening, J.W., 2014. Antibiotic-induced replication stress triggers bacterial competence by increasing gene dosage near the origin. Cell 157 (2), 395-406.

Slavov, N., Botstein, D., 2013. Decoupling nutrient signaling from growth rate causes aerobic glycolysis and deregulation of cell size and gene expression. Mol. Biol. Cell 24 (2), 157-168.

Smits, W.K., Kuipers, O.P., Veening, J.W., 2006. Phenotypic variation in bacteria: the role of feedback regulation. Nat. Rev. Microbiol. 4 (4), 259-271.

Soler-Bistue, A., Mondotte, J.A., Bland, M.J., Val, M.E., Saleh, M.C., Mazel, D., 2015. Genomic location of the major ribosomal protein gene locus determines Vibrio cholerae global growth and infectivity. PLoS Genet. 11 (4).

Solopova, A., van Gestel, J., Weissing, F.J., Bachmann, H., Teusink, B., Kok, J., Kuipers, O.P., 2014. Bet-hedging during bacterial diauxic shift. Proc. Natl. Acad. Sci. U. S. A. 111 (20), 7427-7432.

Stoyan, H., De-Polli, H., Bohm, S., Robertson, G.P., Paul, E.A., 2000. Spatial heterogeneity of soil respiration and related properties at the plant scale. Plant Soil $222(1-2)$, 203-214.

Strassmann, J.E., Zhu, Y., Queller, D.C., 2000. Altruism and social cheating in the social amoeba Dictyostelium discoideum. Nature 408 (6815), 965-967.

Süel, G.M., Kulkarni, R.P., Dworkin, J., Garcia-Ojalvo, J., Elowitz, M.B., 2007. Tunability and noise dependence in differentiation dynamics. Science 315 (5819), 1716-1719.

Takors, R., 2012. Scale-up of microbial processes: impacts, tools and open questions. J. Biotechnol. 160 (1-2), 3-9.

Tan, C., Marguet, P., You, L., 2009. Emergent bistability by a growth-modulating positive feedback circuit. Nat. Chem. Biol. 5 (11), 842-848.

Taniguchi, Y., Choi, P.J., Li, G.W., Chen, H., Babu, M., Hearn, J., Emili, A., Xie, X.S., 2010. Quantifying E. coli proteome and transcriptome with single-molecule sensitivity in single cells. Science 329 (5991), 533-538.

Tegelaar, M., Wösten, H.A.B., 2017. Functional distinction of hyphal compartments. Sci. Rep. 7 (1), 6039.

Tresner, H.D., Hayes, J.A., Backus, E.J., 1967. Morphology of submerged growth of streptomycetes as a taxonomic aid. I. Morphological development of Streptomyces aureofaciens in agitated liquid media. Appl. Microbiol. 15 (5), 1185-1191.

Urem, M., van Rossum, T., Bucca, G., Moolenaar, G.F., Laing, E., Światek-Polatyńska, M.A., Willemse, J., Tenconi, E., Rigali, S., Goosen, N., Smith, C.P., van Wezel, G.P., 2016. OsdR of Streptomyces coelicolor and the dormancy regulator DevR of Mycobacterium tuberculosis control overlapping regulons. mSystems 1 (3), 00014-00016.

van Boxtel, C., van Heerden, J.H., Nordholt, N., Schmidt, P., Bruggeman, F.J., 2017.
Taking chances and making mistakes: non-genetic phenotypic heterogeneity and its consequences for surviving in dynamic environments. J. R. Soc. Interface 14 (132), 20170141.

van Dissel, D., Claessen, D., van Wezel, G.P., 2014. Morphogenesis of streptomyces in submerged cultures. Adv. Appl. Microbiol. 89, 1-45.

van Dissel, D., Claessen, D., Roth, M., van Wezel, G.P., 2015. A novel locus for mycelia aggregation forms a gateway to improved Streptomyces cell factories. Microb. Cell Factories 14 (1), 44.

van Dissel, D., Willemse, J., Zacchetti, B., Claessen, D., Pier, G., van Wezel, G.P., 2018. Production of poly- $\beta-1,6-\mathrm{N}$-acetylglucosamine by MatAB is required for hyphal aggregation and hydrophilic surface adhesion by Streptomyces. Microb. Cell. 5 (6), 269-279.

van Gestel, J., Vlamakis, H., Kolter, R., 2015a. Division of labor in biofilms: the ecology of cell differentiation. Microbiol. Spectr. 3 (2) (MB-0002-2014).

van Gestel, J., Vlamakis, H., Kolter, R., 2015b. From cell differentiation to cell collectives: Bacillus subtilis uses division of labor to migrate. PLoS Biol. 13 (4), e1002141.

van Heerden, J.H., Wortel, M.T., Bruggeman, F.J., Heijnen, J.J., Bollen, Y.J., Planqué, R., Hulshof, J., O'Toole, T.G., Wahl, S.A., Teusink, B., 2014. Lost in transition: start-up of glycolysis yields subpopulations of nongrowing cells. Science 343 (6174), 1245114.

van Veluw, G.J., Petrus, M.L.C., Gubbens, J., de Graaf, R., de Jong, I.P., van Wezel, G.P., Wösten, H.A.B., Claessen, D., 2012. Analysis of two distinct mycelial populations in liquid-grown Streptomyces cultures using a flow cytometry-based proteomics approach. Appl. Microbiol. Biotechnol. 96 (5), 1301-1312.

van Veluw, G.J., Teertstra, W.R., de Bekker, C., Vinck, A., van Beek, N., Muller, W.H., Arentshorst, M., van der Mei, H.C., Ram, A.F.J., Dijksterhuis, J., Wösten, H.A.B., 2013. Heterogeneity in liquid shaken cultures of Aspergillus niger inoculated with melanised conidia or conidia of pigmented mutants. Stud. Mycol. 74, 47-57.

van Wezel, G.P., Krabben, P., Traag, B.A., Keijser, B.J.F., Kerste, R., Vijgenboom, E., Heijnen, J.J., Kraal, B., 2006. Unlocking Streptomyces spp. for use as sustainable industrial production platforms by morphological engineering. Appl. Environ. Microbiol. 72 (8), 5283-5288.

Veening, J.W., Smits, W.K., Hamoen, L.W., Kuipers, O.P., 2006. Single cell analysis of gene expression patterns of competence development and initiation of sporulation in Bacillus subtilis grown on chemically defined media. J. Appl. Microbiol. 101 (3), 531-541.

Veening, J.W., Igoshin, O.A., Eijlander, R.T., Nijland, R., Hamoen, L.W., Kuipers, O.P., 2008a. Transient heterogeneity in extracellular protease production by Bacillus subtilis. Mol. Syst. Biol. 4, 184.

Veening, J.W., Smits, W.K., Kuipers, O.P., 2008b. Bistability, epigenetics, and bet-hedging in bacteria. Annu. Rev. Microbiol. 62, 193-210.

Veening, J.W., Stewart, E.J., Berngruber, T.W., Taddei, F., Kuipers, O.P., Hamoen, L.W., 2008c. Bet-hedging and epigenetic inheritance in bacterial cell development. Proc. Natl. Acad. Sci. U. S. A. 105 (11), 4393-4398.

Velicer, G.J., Kroos, L., Lenski, R.E., 2000. Developmental cheating in the social bacterium Myxococcus xanthus. Nature 404 (6778), 598-601.

Vinck, A., Terlou, M., Pestman, W.R., Martens, E.P., Ram, A.F.J., van den Hondel, C.A.M.J.J., Wösten, H.A.B., 2005. Hyphal differentiation in the exploring mycelium of Aspergillus niger. Mol. Microbiol. 58 (3), 693-699.

Vinck, A., de Bekker, C., Ossin, A., Ohm, R.A., de Vries, R.P., Wösten, H.A.B., 2011 Heterogenic expression of genes encoding secreted proteins at the periphery of Aspergillus niger colonies. Environ. Microbiol. 13 (1), 216-225.

von Ohle, C., Gieseke, A., Nistico, L., Decker, E.M., Debeer, D., Stoodley, P., 2010. Realtime microsensor measurement of local metabolic activities in ex vivo dental biofilms exposed to sucrose and treated with chlorhexidine. Appl. Environ. Microbiol. 76 (7), $2326-2334$.

Walker, G.N., White, N.A., 2005. Fungi: Biology and Applications, 3rd ed. Wiley.

Wang, F.F., Krijgsheld, P., Hulsman, M., de Bekker, C., Müller, W.H., Reinders, M., de Vries, R.P., Wösten, H.A.B., 2015. FluG affects secretion in colonies of Aspergillus niger. Antonie Van Leeuwenhoek 107 (1), 225-240.

Wang, H., Zhao, G., Ding, X., 2017. Morphology engineering of Streptomyces coelicolor M145 by sub-inhibitory concentrations of antibiotics. Sci. Rep. 7 (1), 13226.

Wardell, J.N., Stocks, S.M., Thomas, C.R., Bushell, M.E., 2002. Decreasing the hyphal branching rate of Saccharopolyspora erythraea NRRL 2338 leads to increased resistance to breakage and increased antibiotic production. Biotechnol. Bioeng. 78 (2), 141-146.

Wessels, J.G.H., 1988. A steady-state model for apical wall growth in fungi. Acta Bot. Neerl. 37 (1), 3-16.

Wessels, J.G.H., 1993. Wall growth, protein excretion and morphogenesis in fungi. New Phytol. 123 (3), 397-413.

Wilkinson, D.J., 2009. Stochastic modelling for quantitative description of heterogeneous biological systems. Nat. Rev. Genet. 10 (2), 122-133.

Wireman, J.W., Dworkin, M., 1977. Developmentally induced autolysis during fruiting body formation by Myxococcus xanthus. J. Bacteriol. 129 (2), 798-802.

Wittier, R., Baumgartl, H., Lübbers, D.W., Schügerl, K., 1986. Investigations of oxygen transfer into Penicillium chrysogenum pellets by microprobe measurements. Biotechnol. Bioeng. 28 (7), 1024-1036.

Wösten, H.A.B., Moukha, S.M., Sietsma, J.H., Wessels, J.G.H., 1991. Localization of growth and secretion of proteins in Aspergillus niger. J. Gen. Microbiol. 137 (8), 2017-2023.

Wösten, H.A.B., van Veluw, G.J., de Bekker, C., Krijgsheld, P., 2013. Heterogeneity in the mycelium: implications for the use of fungi as cell factories. Biotechnol. Lett. 35 (8), $1155-1164$.

Wu, F., Dekker, C., 2016. Nanofabricated structures and microfluidic devices for bacteria: from techniques to biology. Chem. Soc. Rev. 45 (2), 268-280.

Xu, H., Chater, K.F., Deng, Z., Tao, M., 2008. A cellulose synthase-like protein involved in hyphal tip growth and morphological differentiation in Streptomyces. J. Bacteriol. 190 
(14), 4971-4978.

Yagüe, P., López-García, M.T., Rioseras, B., Sánchez, J., Manteca, A., 2013. Pre-sporulation stages of Streptomyces differentiation: state-of-the-art and future perspectives. FEMS Microbiol. Lett. 342 (2), 79-88.

Yagüe, P., Rodríguez-García, A., López-García, M.T., Rioseras, B., Martin, J.F., Sánchez, J., Manteca, A., 2014. Transcriptomic analysis of liquid non-sporulating Streptomyces coelicolor cultures demonstrates the existence of a complex differentiation comparable to that occurring in solid sporulating cultures. PLoS One 9 (1), e86296.

Yagüe, P., Willemse, J., Koning, R.I., Rioseras, B., Lopez-García, M.T., GonzalezQuiñonez, N., Lopez-Iglesias, C., Shliaha, P.V., Rogowska-Wrzesinska, A., Koster, A.J., Jensen, O.N., van Wezel, G.P., Manteca, A., 2016. Subcompartmentalization by cross-membranes during early growth of Streptomyces hyphae. Nat. Commun. 7,
12467.

Yegneswaran, P.K., Gray, M.R., Thompson, B.G., 1991. Effect of dissolved oxygen control on growth and antibiotic production in Streptomyces clavuligerus fermentations. Biotechnol. Prog. 7 (3), 246-250.

Young, J.W., Locke, J.C.W., Elowitz, M.B., 2013. Rate of environmental change determines stress response specificity. Proc. Natl. Acad. Sci. U. S. A. 110 (10), 4140-4145.

Zacchetti, B., Willemse, J., Recter, B., van Dissel, D., van Wezel, G.P., Wösten, H.A.B., Claessen, D., 2016. Aggregation of germlings is a major contributing factor towards mycelial heterogeneity of Streptomyces. Sci. Rep. 6, 27045.

Zhang, Z., Claessen, D., Rozen, D.E., 2016. Understanding microbial divisions of labor. Front. Microbiol. 7, 2070. 